\title{
A Comparison of Yields On Futures Contracts and Implied Forward Rates
}

\author{
RICHARD W. LANG and ROBERT H. RASCHE
}

\section{(3)} INCE the introduction of futures trading in 3-month Treasury bills in 1976, yields on these futures contracts have been examined for clues as to market expectations of the future course of interest rates. Although there are difficulties in isolating these expectations, the yields on futures contracts do embody information about market expectations of future interest rates. ${ }^{1}$ However, similar information is also embodied in the forward rates of interest that are implicit in the spot market yield curve.

Yields on Treasury bill futures contracts (futures rates) are essentially the market counterpart to the implied forward rates embodied in the Treasury yield curve. The correspondence between yields on financial futures contracts and forward rates derived from a yield curve is readily apparent in the work of Sir John Hicks. Hicks interpreted the term structure of interest rates as a futures market for loans in formulating his theory about the relationship of long-and short-term interest rates, ${ }^{2}$ To the extent that futures rates and forward rates represent the yield on the same type of loan contract, market traders will arbitrage between yields in the futures market and yields in the spot market (from which implied forward rates are derived) if profitable trading opportunities exist. In this case, it would not be sumprising to find yields on Treasmy bill futures contracts to be closely related to implied forward rates embodied in the Treasury yield curve. This paper compares yields on 3-month Treasury bill futures contracts with forward rates derived from spot yields on Treasury securities, for comparable periods, to examine how closely these interest rates are related. Specifically, this paper tests the hypothesis that futures rates are equal to implied for-

1For a discussion of these difficulties, see Albert E. Burger Rixhard W. Eang and Robert H. Rasche, "The Treasury Bil Futures Market and Market Expectations of Interest Rates," this Review (June 1974), pp. 2-9.

J. R. Hicks, Value and Capital: An Inquiry into Some Fundamental Principles of Economic Theory, 2nd ed. (Oxford: Clarendon Press, 1946), pp. 144-47. ward rates, and finds that this hypothesis must be rejected. Various explanations as to why the rates are not equal are then examined.

Recently, William Poole and others have argued that the yields on 3-month "Treasury bill futures contracts can be expected to be less than the corresponding implied forward rates, that these futures rates are unbiased market estimates of future Treasury bill spot rates, and that it is not necessary to allow for risk premia when using yields on futures contracts to measure market expectations of future interest rates. ${ }^{3}$ If these arguments are correct, a great deal of empirical work in economics that includes variables on interest rate expectations will be greatly simplified. In addition, such conclusions would allow policymakers to easily assess the differences between their own interest rate forecasts and the market's expectations of the future course of interest rates. As Poole notes, policymakers face difficult problems when market interest rate forecasts differ from the policymakers" forecasts, since they then must decide whether their own estimates of economic activity are incorrect or whether the market is misinterpreting the policymakers' plans." Unfortunately, the restuts reported in this paper do not support these conclusions about the relationship between futures rates and forward rates for futures contracts, except for the ones closest to delivery, which were the ones investigated by Poole. Extrapolation of Poole's conclusions to other futures contracts is therefore unwarranted, and other explanations for the relationship between forward and futures rates must be explored. One factor considered here is the possibility of default risk affecting yields on futures contracts.

\footnotetext{
"William Poole, “Using T-Bull Futures to Gauge Interest-Rate Expectations," Federal Reserve Bank of San Francisco Economic Retiew (Spring 1978), pp. 7,14 and 15 ; and Kermeth Froewiss and Michael Gorham, "Everyman's Interest Rate Torecast," Federal Reserve Bank of San Francisco Weekly Letter (Septenber 8, 1978), D. 1 .

fPoole, "Using T-Bill Futmres to Gauge Interest-Rate Lrpectations," pp. 16-17.
} 


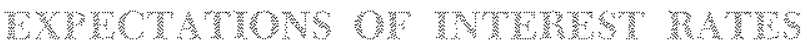

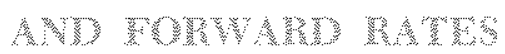

Expectations of future interest rates play an important role in many areas of economics; topics in both micro- and macroeconomics deal with interest rate expectations. Since such expectational variables generally are not observable, researchers have only been able to proxy them by using various substitutes, such as by constructing expectational variables on the basis of the past history of each variable. This approach is problematical in that when such expectational proxies are used in empirical research, a joint test is made: both the hypothesis and the assumed expectations-formation mechanism are tested.

One alternative to such joint tests is to survey a specific group (such as financial consultants) as to their expectations of interest rates for various future periods. Such a survey has been reported since 1969 in the Goldsmith and Nagan Bond and Money Market Letter. ${ }^{5}$ However, such surveys are subject to problems that may limit their usefulness. One problem is basically statistical, but another deals with the timing of the survey. The Goldsmith-Nagan survey is quarterly, which makes its use for shorter periods very difficult.

An alternative approach that allows the use of daily data focuses upon changes in interest rate expectations rather than levels, and is based upon changes in the shape of the yield curve from one date to another. A yield curve relates the yields-to-maturity of a group of securities to their terms-to-maturity, for securities with similar characteristics other than maturity. In particular, all of the securities used in constructing a yield curve have similar default risk. For example, yield curves are usually drawn for Treasury securities, or for corporate Aaa bonds, as of a particular date. The yield curve indicates the structure of interest rates on a given date for securities with the same risk of default and different terms-to-maturity.

Changes in the shape of the yield curve from one date to another involve changes in implied forward rates. A forward rate is the yield on a loan or investment over some period beginning at a specified future time. Such a forward rate can be obtained by an appropriate combination of buying and selling bonds outstanding. For example, by selling a 1-year bond

5 Other interest rate surveys have been collected by various researchers, but are not regularly published. For example, see Edward J. Kane and Burton G. Makkiel, "The Term Structure of Interest Rates: An Analysis of a Survey of Interest-Rate Expectations," The Feview of Economics and Statistics (August 1967), pp. 343-55. and buying a 2-year bond, a 1-year investment is effectively made that will begin 1 year hence at a rate of interest established by the difference in the spot market yields for the 1- and 2-year bonds. The forward rate on this loan is defined by:

$$
\left(1+{ }_{1} \mathrm{~F}_{1}\right)=\frac{\left(1+\mathrm{R}_{2}\right)^{2}}{\left(1+\mathrm{R}_{1}\right)^{1}}
$$

where ${ }_{1} F_{1}$ is the forward rate on a 1 -year loan to begin in 1 year, $R_{2}$ is the spot rate on 2-year bonds, and $R_{1}$ is the spot rate on 1-year bonds.

More generally, for a 1-period investment to begin $\mathrm{n}-1$ periods in the future the forward rate is:

$$
\left(1+E_{n-1} F_{1}\right)=\frac{\left(1+R_{n}\right)^{n}}{\left(1+R_{n-1}\right)^{n-1}}
$$

where ${ }_{n-1} F_{1}$ is the forward rate on a 1-period loan to begin in $n-1$ periods, $R_{n}$ is the spot rate on n-period bonds, and $R_{n-1}$ is the spot rate on (n-1)-period bonds.

Thus, the yield curve at any given point in time im plies a set of 1-period forward rates to prevail on forward (or future) transactions. Such forward rates have economic content, however, only if the implied transactions are possible in the market, and can be carried out by market traders. ${ }^{6}$

In theories of the term structure of interest rates, the forward rates $\left({ }_{n-1} F_{1}\right)$ are often decomposed into a 1-period expected rate $\left({ }_{n-1} E_{t}\right)$ plus a premium (a liquidity premium associated with interest-rate risk or a term premium associated with investors' preferences for bonds with specific ranges of maturities). ${ }^{7}$

$$
{ }_{n-1} F_{1}=n_{n-1} E_{1}+\text { Premium }
$$

For a set of 1-period forward rates on a given date, there is then a set of 1-period expected rates stretching out into the future. Under the assumption that the premia are stable over time, changes in the structure of interest rates (measured by changes in the yield curve) reflect changes in interest rate expectations. Thus, by examining the changes in the implied forward rates contained in the term structure, researchers can obtain an estimate of the changes in interest rate expectations, even though the level of expected interest rates is not readily estimable.

F F or a thorough discussion of yield curves, forward rates of interest, and the term structure, see Burton Cordon Malkiel, The Term Structure of Interest Rates: Expectations and Behavior Patterns (Princeton: Princeton University Press, 1966), Chapters I and II.

${ }^{7}$ Malkiel, p, 26; Franco Modigliani and Richard Sutch, "Debt Management and the Term Structure of Interest Rates,"Journal of Political Economy (Supplement: August 1967), pp. 57 I-73; Charles $\mathrm{R}$. Nelson, The Term Structure of Interest Rates (New York: Basic Books, 1972 ) pp. 20 and 28-31. 
However, such calculations are time consuming and costly - in terms of both data collection and computer time. One must obtain quotations on securities outstanding (e.g. Treasury issues), fill in missing data points by estimating a yield curve, then calculate forward rates. This is a difficult task if done monthly, and expensive to do weekly or daily. As a result, it is expensive to use yield curve data to assess the effect of new information about economic policies or of the state of the economy on expectations of future interest rates.

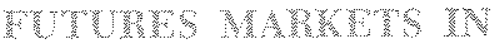

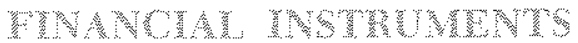

Starting in the fall of 1975 , the difficulties of examining changes in market expectations of future interest rates on a weekly or daily basis have been alleviated. Trading in futures contracts in financial instruments began to develop in late 1975 , and currently there are futures markets in seven financial instruments. ${ }^{8}$ This paper focuses on the futures market in 3-month Treasury bills.

Futures markets in 3-month Treasury bills allow us to observe directly the yields or prices on 3-month bills to be delivered at certain dates in the future. Thus, they are the market counterpart of the implied forward loans or investments which can be constructed from Treasury yield curve data. But instead of requiring large efforts at data collection, estimation, and calculation, these yields are readily available from daily quotations in The Wall Street Journal and other newspapers.

As new information about the economy or economic policy becomes avalable to market traders, this information is incorporated into the market prices and yields of Treasury bill futures contracts. To the extent that such new information changes market expectations of interest rates, it is reffected in changes in the Treasury bill futures rates. Yields on futures contracts could also be broken down into expectational and premium components, just as in the case of forward rates implicit in the yield curve. Again, the level of expected future interest rates may not be readily estimable, but changes in market expectations of future interest rates can be observed from changes in yields on futures contracts, under the assumption that the premia are stable. ${ }^{*}$

8Currently there are futures markets in 3-month and 1 -year Treasury bills, 15-year Treasury bonds, 3-month commercial paper, and three GNMA instruments. 3 number of other thtures markets in ther financial instruments have also been proposed.

"Bufger, Lang, and Rasche. "The "Treasury Bin Futures Market and Market Expectations of Interest hates," pp. $4-5$.

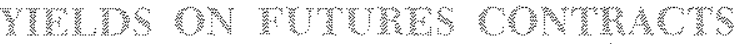

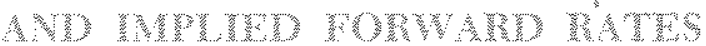

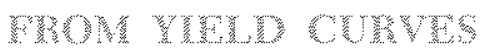

Since implied forward rates calculated from the yield curve are, in theory, rates on forward loans or investments such as those actually made in the Treasury bill futures market, the question arises as to whether yields on 3-month Treasury bill futures contracts are equal to 3 -month forward rates calculated from the Treasury yield curve. It would be convenient if the two sets of yields were equal, so that we would not have to be concerned with any separate informational content of either data set (especially since yields on Treasury bill futures are easier to obtain).

A test for the equality of the two yields, as of a quotation date, can be made by comparing yields on Treasury bill futures contracts with yields on implied forward contracts for the same periods. First, we choose a set of quotation dates. Then, we obtain the yields on Treasury bill futures contracts on those dates for each available delivery date. Next, we obtain quotations on U.S. Treasury securities outstanding on those same quotation dates. From these data we cal culate implied 3-month forward rates that match the 3-month Treasury bill futures contracts. Finally, we calculate the difference (in absolute value) between the two sets of rates to determine whether they are significantly different from each other.

\section{The Whes}

The selection of quotation dates for yields on Treasury bill futures contracts and yields on outstanding Treastry securities were obtained by random selections of thirty quotation dates from each of three periods of roughly equal length - eight to nine months. ${ }^{10}$ The first thirty quotation dates were taken from the period March 1, 1976 to November 30, 1976 (Period I); the second thirty quotation dates were taken from the period December 1, 1976 to July 31 , 1977 (Period 1 ) ; and the last thirty quotation dates were taken from the period August 1, 1977 to March 31, 1978 (Period III). Yields on the avalable futures contracts for each quotation date were based on the settlement prices obtained from the "Daily Information Bulletin" of the International Monetary Market of the Chicago Mercantile Exchange. Yields on outstanding U.S. Treasury securities used to construct forward rates for each quotation date were obtained

\footnotetext{
10 he random numbers were obtained from The Rand Corporation, $A$ Millon Random Dirts wh 100,000 Nomal Desiates (Glenco, Ilinois: The free Press, 1955 ).
} 


\begin{tabular}{|c|c|c|c|c|c|c|c|c|}
\hline & Diff & Summa & $\begin{array}{l}\text { Statistics } \\
\text { sates }\end{array}$ & $\begin{array}{l}\text { for Abso } \\
\text { Less For } \\
\quad \mathrm{Co}\end{array}$ & Rates & & & \\
\hline & 1 & 2 & 3 & 4 & 5 & 6 & 7 & 8 \\
\hline \multirow{2}{*}{\multicolumn{9}{|c|}{$\begin{array}{l}\text { Pertod } 1 \\
(3 / 1 / 76,1) / 30 / 76)\end{array}$}} \\
\hline & & & & & & & & \\
\hline \multicolumn{9}{|l|}{ Mean. $\bar{x}$ s } \\
\hline Standard Deviation, $s$ & 011 & 0,12 & 0,21 & 0,34 & 0.45 & 0.31 & & \\
\hline Number of observations $N$ & 60.4 & 70,30 & 30, & 29 & 23.18 & 546 & & \\
\hline \multicolumn{9}{|l|}{ Period I } \\
\hline \multicolumn{9}{|l|}{$112 / 1 / 76 / 7 / 3 / 177)$} \\
\hline $\mathrm{Meon}, \mathrm{X}$ & 000 & 0,14 & 0,34 & 0,37 & 0.63 & 088 & 0.97 & 1.43 \\
\hline Stondard Deviolion, $s$ & 0.06 & 0.11 & 0,20 & 0.26 & 0,35 & 0.34 & 026 & 0.44 \\
\hline Number of observatons & 30,2 & 30 & $30 \mathrm{n} 31$ & 70 & 90 & 29 & 12 & 12 \\
\hline \multirow{2}{*}{\multicolumn{9}{|c|}{$\begin{array}{l}\text { Period } 11 /, \\
18 / 1 / 77,3 / 31 / 78)\end{array}$}} \\
\hline & & & & & & & & \\
\hline Mean, $\mathrm{X}$ & 019 & 0.26 & 0.16 & 0,34 & 0.48 & 0.56 & 0.55 & 1.01 \\
\hline Stendard Deviation, $s$ & 0,13 & 0.15 & 0.11 & 0,22 & 029 & 0.27 & 031 & 0,36 \\
\hline Number of observations, $\mathrm{N}$ & 30,01 & 30,9 & 30,97 & 30 & 30,07 & 30 & 30 & $\begin{array}{l}28 \\
1485\end{array}$ \\
\hline
\end{tabular}

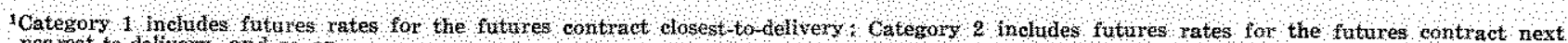
nearest-to-delivery, and so on

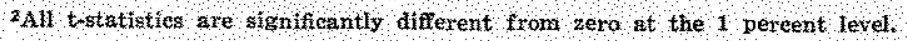

from the Federal Reserve Bank of New York's "Composite Closing Quotations for U.S. Government Securities." All yields were converted from a discount basis to a bond equivalent yield basis.

Forward rates were calculated for each quotation date to match up with each available Treasury bill futures contract. Thus, if a futures contract were to be delivered in 30 days, at which time the delivered Treasury bills would have 90 days to maturity, a forward rate was calculated using the yields on an outstanding Treasury bill maturing in 30 days and an outstanding Treasury bill maturing in 120 days. If no bills were outstanding with the exact number of days to maturity, say 120 , then the yield was estimated by linearly interpolating from the yields on two securities with maturities surrounding 120 days - say one with 130 days and one with 115 days. The resulting forward rate is the implied yield on a loan or "security" that begins in 30 days and has 90 days to maturity - the same time frame as the futures contract. ${ }^{11}$

\footnotetext{
11Spot rates used to calculate forward rates were the average of the bid and asked yields in the spot market. For futures contracts to be delivered more than one year in the future, yields on Treasury coupon securities were used (since Treasury bills are not available) to calculate the forward rates.
}

Once the forward rates matching the available futures contracts were calculated for each quotation date, they were compared to the yields on the futures contracts (futures rates) by taking the absolute difference between the two. For each quotation date, these differences were categorized as being associated with the futures contract nearest-to-delivery (Category 1), next nearest-to-delivery (Category 2), and so on. All the available contracts for each quotation date were categorized in this way. When the market was first formed in 1976, only four contracts were traded, extending out one year into the future. As trading in Treasury bill futures has increased, the number of contracts has been extended. By March 1978, the end of the third sample, there were eight contracts traded,

(This introduces a slight measurement error in the calculation of the forward rates since the formulae given below and in the text assume that the spot rates used are for non-colipon securities.) The formula used to calculate the forward rates is that given by Richard Roll, The Behavior of Interest Rates: An Application of the Efficient Market Model to U.S. Treasury Bills (New York: Basic Books, Inc., 1970), p. 16:

$$
n-9 F_{91}=\frac{n R_{n}-(n-91) R_{n-91}}{91}
$$

A comparison of the above formula's estimates of forward rates with estinates based on the traditional formula given in the text showed only minor differences. Consequently, the above formula was used for computational ease. 
extending out two years into the future. Consequently, the number of observations in Categories 4 through 8 are not always equal to 30 for each sample, and the first sample does not have as many categories as the last two samples.

\section{mestis}

Summary statistics for the futures rates minus the associated forward rates are given in Table I for each category in each sample period. The mean of the absolute value of the differences between the rates are given for each category, as well as the standard deviation and the number of observations. For each category in each sample, the hypothesis that the futures rate is equal to the associated forward rate was tested by determining whether the mean absolute difference in each category is significantly different from zero. The $t$-value for each test is also given in Table $I$.

The two futures contracts nearest to delivery (Categories 1 and 2) tended to have the smallest mean absolute differences between the futures and forward rates, while the contracts furthest from delivery tended to have the largest mean absolute differences. All of the mean absolute differences were significantly different from zero at the 1 percent level. Thus, although the mean absolute differences between the futures and forward rates for the two futures contracts closest to delivery (Categories 1 and 2) were generally less than 20 basis points, the hypothesis that the rates are equal is rejected in each sample.

Samples were taken from three different time periods in order to determine whether the differences between the futures and forward rates have narrowed over time. Such an observation would suggest that in its first year of trading the futures market might have been poorly developed, or "thin," in terms of the number of traders in the market and the availability of information about the market. We could then expect that as the volume of trading in this market increased and information about possible arbitrage opportunities between futures and spot markets was more effectively utilized, the differences between the futures and forward rates would decrease between the first and second samples, and would decrease further between the second and third samples.

Neither casual observation of the data in Table I nor statistical tests for significant differences across sample periods support the hypothesis that the differences between futures and forward rates have consistently narrowed over time. Table II presents the results of statistical tests to determine whether the mean ab-

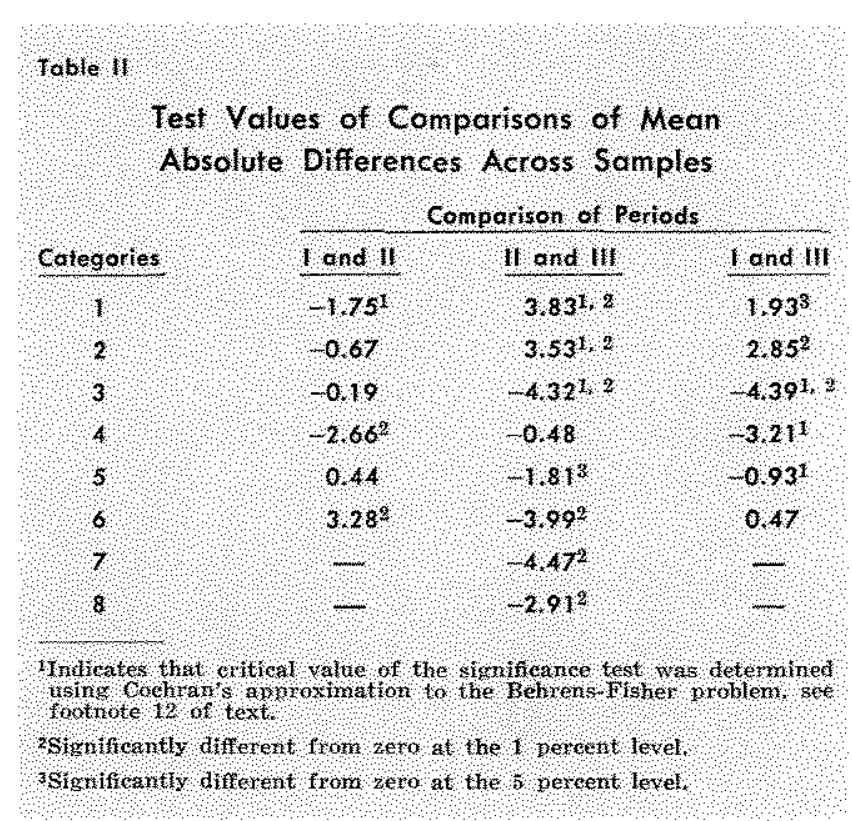

solute difference in each category of a sample was significantly different from the mean absolute difference in the same category in the other two samples. ${ }^{12}$ The results shown in Table II do not present a consistent pattern over time.

For example, a comparison of the mean absolute differences between the first and second samples for Categories 1,2, and 3 indicates that the means are not significantly different from each other at the 5 percent level. Thus, the slight declines in the mean absolute differences for the first three categories nearest to delivery between the first and second samples do not represent statistically significant differences in the relationship of the futures and forward rates. On the other hand, the increases in the mean absolute dif ferences between the second and third samples for the first two categories are statistically significant, as is the decrease for the third category.

On the basis of this evidence, we cannot conclude that the differences between the futures and forward rates have been narrowing consistently over time as the futures market for Treasury bills has become more developed. Other explanations for the statistically sig-

$12 \mathrm{~A}$ tutest for the difference between two means generally tem quires the assumption that the variances of the two samples are equal. When this assumption cannot be made, one is faced with what has been ealled a "BehrenswFisher problem." An approximation to the t-test due to Cochran that provides a solution is given in George $W$. Snedecor and William G. Cochran, Statistical Methods, 6th ed. (Ames, Lowa: Iowa State University Press, 1967), pp. 114-16. This method was used in calculating the t-values and their signiffance in rable II for the cases where an F-test of the equality of the variances of the samples being compared rejected the hypothesis of equality. 


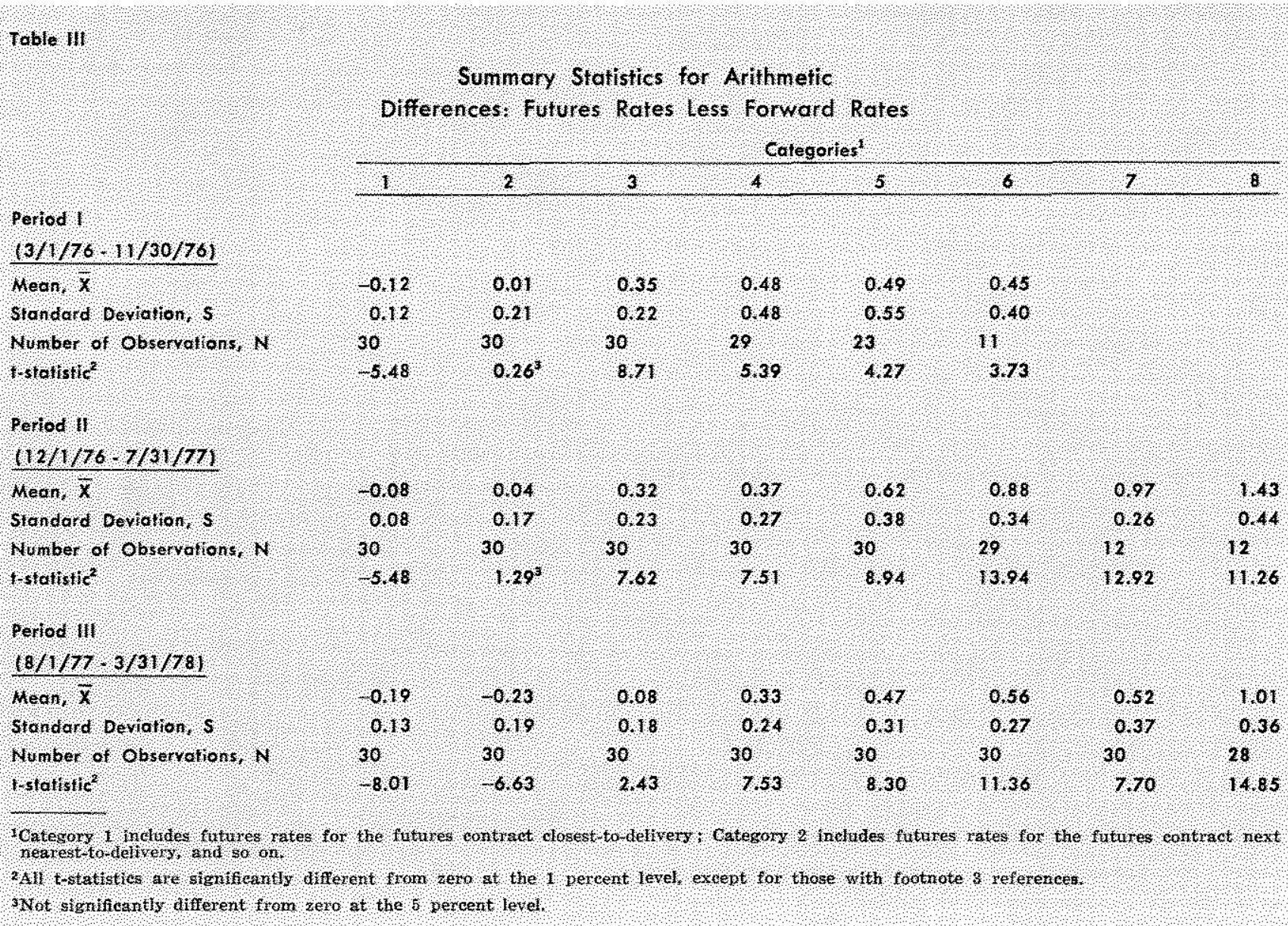

nificant spreads between the futtres and forward rates must be explored.

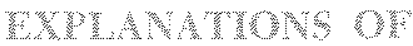

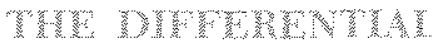

Given that there are significant differences between futures and forward rates that have not declined over time, the question arises as to whether or not these differences are systematic. If the differences are systematic, can we identify some factor or factors that would cause such systematic differences? A further issue is to re-examine the argument that market traders will arbitrage away differences between futures and forward rates. This argument was based on the assumption that a futures contract is essentially identical to an implied forward contract. If a futures contract is substantially different from an implied forward contract, then market traders will not necessarily drive futures rates to equality with forward rates. However, even if a futures contract is essentially identical to an implied forward contract, the existence of transactions costs in trading spot and future Treasury bills may provide few profitable arbitrage opportunities to traders. In this case, trading in spot and futures markets will not necessarily result in equalizing futures and forward rates.

To examine whether there are systematic differences between futures and forward rates, the mean arithmetic difference for each category in each sample period is given in Table III. The arithmetic differences are systematically negative in all periods for Category 1 , zero or negative for Category 2 , and systematically positive in all periods for Categories 3 through 8 . With the exception of Category 2 in Periods I and II, all of the arithmetic differences are significantly different from zero. Thus, futures rates for contracts closest to delivery are generally lower than their associated forward rates, while futures rates for later-dated contracts are generally higher than their associated forward rates. Explanations of the spread between futures and forward rates must be able to account for both the spread itself and its change in sign as the delivery date is extended into the future. 


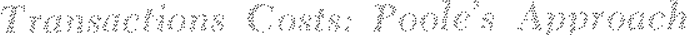

In a recent article, William Poole hypothesizes that futures and forward rates should not be equal because of the effect of transactions costs on these yields. ${ }^{13} \mathrm{He}$ argues that transactions costs are basically zero for futures contracts but positive for trades in the spot market. Other factors affecting futures and forward rates (such as term or liquidity premia and interest rate expectations) are assumed to be about the same, while the effect of transactions costs would tend to increase forward rates. Consequently, Poole concludes that futures rates should be lower than forward rates. ${ }^{14}$

Poole obtains empirical support for his hypothesis by examining the futures contract closest to delivery (our Category 1). He finds that the mean (arithmetic) difference between futures and forward rates is indeed negative, indicating that futures rates are lower than forward rates. The mean difference also tends to be significantly different from zero; a result consistent with that reported in our Table III.

In Poole's subsequent discussion of the policy implications of the Treasury bill futures market, he assumes that his findings apply to all futures maturities (i.e., all categories in Table III), not just to the contract closest to delivery. ${ }^{15}$ This assumption is not supported by our data. The results shown in Table III indicate that Poole's hypothesis holds only for Categories 1 and 2 (the two contracts closest to delivery). For the other contracts that are delivered further in the future, the futures rates are higher than the forward rates contrary to Poole's hypothesis.

Poole seems to argue that futures rates are close to being equivalent to the market's expectations of future interest rates.

Quotes on the nearest maturity in the bill futures market can, therefore, be interpreted for all practical purposes as the market's unbiased estimates of the future spot rates on 13-week bills. ${ }^{16}$

If the findings in the previous section apply to all future maturities, then the differences between the futures rates and the realized spot rates over the last two years reflect genuine expectational errors rather than term premiums attached to the futures rates. ${ }^{17}$

\footnotetext{
13Poole, "Using T-Bill Futures to Gauge Interest-Rate Expectations," pp. 7-19.

14 Ibid., p. 14 .

15 Ibid., p. 15.

16 Ibid.

17 Ibid.
}

The evidence presented here indicates that it is misleading to extrapolate from the evidence on the futures contract closest-to-delivery to the later-dated contracts. Futures rates on the later-dated contracts are generally 50 to 100 basis points higher than their associated forward rates, which suggests the existence of some substantial differences between the factors affecting the futures and forward rates.

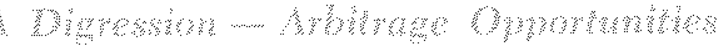

The relatively large and statistically significant differences in Table III between the futures and forward rates for the later-dated futures contracts raises the issue of whether substantial arbitrage opportunities exist for these contracts. Poole investigated this issue for the contract closest to delivery and found that few arbitrage opportunities exist.

Poole defined upper and lower critical points for profitable arbitrage for the futures rate given the spot yields, taking into account transactions costs. Values of the futures rates that lie between these upper and lower critical points indicate that profitable arbitrage opportunities do not exist. Poole calculated upper and lower arbitrage points using daily data between January 6,1976 and June 23,1977 for the contract closest to delivery. He found that profitable arbitrage opportunities rarely existed, and were small in magnitude when they did exist.

By converting Poole's formulae for the upper and lower arbitrage points to a bond equivalent yield basis (from his discount yield basis), we applied his approach to our three samples of data. In doing so, the formulae are not exact since the transactions costs associated with arbitraging the futures contracts further from delivery are larger than for the contracts closest to delivery. This is because maturities for securities in the spot market do not exactly match up with the maturities associated with the futures contract. In addition, for futures contracts to be delivered more than one year out, yields on Treasury coupon securities were used to calculate forward rates (see footnote 11). Consecuently, transactions costs associated with arbitraging the later-dated contracts would be higher than the ones used in Poole's formulae. This means that our adoption of Poole's formulae understates the upper arbitrage point, and overstates the lower arbitrage point. The spread between the upper and lower points is therefore understated, so that there may appear to be arbitrage opportunities which would not in fact be profitable if we took all the transactions costs into account. 
Nevertheless, the application of Poole's formulae will at least indicate the extent of arbitrage opportunities using a conservative estimate of the transactions costs involved. For each category of contract in each sample period, Table IV shows the number of futures rates that are above the upper arbitrage point, below the lower arbitrage point, or within the upper and lower points. Table IV also shows the number of futures rates that are within or "close" to (defined as within .10 of) the upper or lower arbitrage points.

Aggregating over all three sample periods, the results for Categories 1 and 2 tend to support Poole's findings. Over 75 percent of the futures rates in Categories 1 and 2 are within, or "close" to, the upper and lower arbitrage points, taking all three periods as a whole. However, the percentage for Period III alone is considerably lower than for Periods I and II. Furthermore, the percentage tends to decline as the delivery date extends further into the future. For categories 6,7 , and 8 over all three sample periods, the number of futures rates within, or "close" to, the upper and lower arbitrage points are only 45,36 , and 5 percent, respectively. Of course, the calculation of the arbitrage points for these later-dated contracts are most likely to be subject to error since they are based on yields on Treasury coupon securities rather than Treasury bills, and since the spot maturities of the securities used do not match up exactly with the later-dated futures contracts. Nevertheless, there are still some puzzling features about the results.

First, when the futures rate falls outside the upper and lower arbitrage points for the two contracts closest to delivery (Categories 1 and 2), it is almost always below the lower arbitrage point. Futures rates for later-dated contracts, on the other hand, are almost always above the upper arbitrage point when they fall outside the upper and lower bounds. Second, when the futures rate is above the upper arbitrage point for the later-dated contracts, the difference between the futures rate and the upper bound ranges from less than 10 basis points to over 100 basis points (one full percentage point), and generally averages over 30 basis points in each category. Thus, unless the calculations of the upper arbitrage points for the laterdated contracts are substantially underestimated, it appears that systematic arbitrage opportunities frequently existed for the later-dated futures contracts during our sample periods. ${ }^{18}$

If profitable arbitrage opportunities exist but are not acted upon by market traders, then we should not expect futures and forward rates to be as closely related as we had earlier suggested, and we certainly should not expect them to be equalized. Such a situation could explain the results obtained earlier, that futures rates and forward rates are not equal. However, such a situation implies that there is a market

\footnotetext{
18 That frequent arbitrage opportunities have existed in the futures market has also been argued in two other papers. See Donald I. Puglisi, "Is the Futures Market for Treasury Bils Efforent?" The Joumal of Portfolio Management (Winter 1978), pp 64-67; and Anthony I. Vignola and Charles J. Dale, "Is the Futures Manket for Treasury Bills Effetent: A Comment, The Journal of Porfolio Management (Winter 1979), forthcomirig.
} 
inefficiency or failure present. Such inefficiency or failure could be due to lack of information about trading opportunities or to institutional constraints on trading. Since information about trading in futures markets is likely to improve over time, and since institutional constraints encourage innovations that reduce their effectiveness, such a situation of market inefficiency or failure will probably be reduced over time.

If transactions costs are substantially larger than those used here, it may be that profitable arbitrage opportunities rarely existed despite the large spreads between the futures and forward rates for the laterdated contracts. In this case, we again should not expect futures and forward rates to be as closely related as was earlier suggested. Given transactions costs, futtres rates and forward rates may not be equalized.

However, Poole's argument based on transactions costs led him to conclude that futures rates should be lower than forward rates. Even though transactions costs might explain why futures rates and forward rates are not equalized, it is still puzzling that futures rates are substantially higher than their associated forward rates for the later-dated contracts, contrary to Poole's argument. This suggests that factors other than transactions costs may affect futures rates differently than forward rates, and we now turn to a consideration of these other factors.

\section{Whall wat}

Poole implicitly assumes that factors other than transactions costs have the same effects on both futures and forward rates. Thus, since transactions costs are expected to increase forward rates, and since transactions costs are close to zero for futures contracts, Poole concludes that futures rates will be less than their associated forward rates. ${ }^{19}$ That this conclusion is not supported by evidence for the laterdated futures contracts suggests that there are other factors embodied in futures and forward rates that have effects in the opposite direction to the transactions-cost effect discussed by Poole. Furthermore, this effect is stronger for the later-dated futures contracts than for those close to delivery.

Both futures rates and forward rates can be broken down into expectational and premium components. Since one-period expectations of future interest rates should be the same in both rates, we must consider the premium components of these rates. The premium

19) Poole, "Using T-Bill Futures to Gange Interest-Rate Expectations," p. 14 . associated with a forward or futures rate is generally considered to be a liquidity premium associated with interest-rate risk, or a term premium associated with investors' maturity preferences.

For a liquidity premium embodied in a futures rate to be different from the liquidity premium embodied in a comparable forward rate implies that the interestrate risk associated with the futtres contract is different than that associated with the comparable implied forward contract. For futures rates to be higher than forward rates for the later-dated contracts as a result of differences in liquidity premia, a given rise in interest rates would have to generate a larger risk of capital loss in the futures contract than in the implied forward contract. It is not obvious why this would be the case.

For a term premium embodied in a futures rate to be different from the term premium embodied in a comparable forward rate implies that investors' maturity preferences vary both across maturities and across financial instruments. It is again not obvious why this would be the case.

One factor that has been ignored in the discussion of futures contracts is default risk. Treasury bills traded in the spot market are considered to be default free. Hence, implied forward rates would not embody premia related to default risk. However, a futures contract is not guaranteed by the U.S. Government, but is rather guaranteed by the exchange on which it is traded. Although the futures contract involves delivery of Treasury bills that are default free, the contract itself is not default free. Consequently, the futures rate may contain a risk premium associated with default risk.

This default risk factor would be more important for the futures contracts that are further from delivery, those for which Poole's hypothesis fails to be supported in our samples. The furthest-dated futures contracts involve delivery of Treasury bills which have not yet been issued; they do not exist. The possibility exists, although it may be small, that there would not be a sufficient amount of 3 -month Treasury bills available to meet the deliveries required by the number of open futures contracts held for delivery. Although the Chicago Mercantile Exchange guarantees that a settlement would be made, at least a monetary settlement, the item promised for delivery (3-month Treasury bills) may not be delivered. ${ }^{20}$

20Defauts on futures contracts for commodities are rare, but result in quite an uproar when they do occur. A recent example was the May 1976 default on the delivery of Maine 
This risk of default, or risk of non-delivery of the Treasury bills, would tend to make yields on the laterdated futures contracts higher than the yields on the two contracts closest to delivery (where Treasury bills that can be used for delivery have been issued), other things constant. The results shown in Table III are consistent with this hypothesis. However, whether or not the size of the spreads between the futures and forward rates for the later-dated contracts can be accounted for solely by default risk is an open question.

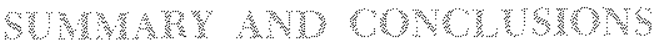

Since yields on futures contracts are the market counterpart of implied forward rates of interest derived from the yield curve, the hypothesis that futures rates and forward rates are identical was tested using data from the Treasury bill futures market and the spot market for Treasury securities. The results indicate that futures rates are significantly different from the associated forward rates. Furthermore, the differences between the two rates have not narrowed consistently over time. Thus, it is difficult to attribute the significant differences between the two rates as being due to the initial "thinness" in the development of the Treasury bill futures market.

Poole's argument that the two rates should not be equal, but that the futures rate should be below the forward rate, was also examined. Poole's results were based on the effect of transactions costs on forward and futures rates, and were supported by evidence using the futures contract closest to delivery. Results from our samples for later-dated futures contracts do not support Poole's hypothesis. Instead, we find that the futures rates are consistently above the forward rates for the later-dated contracts. Thus, Poole's

potato futures. Recently a bill was introduced in Congress that would ban all futures trading in potatoes. results on the contract closest-to-delivery should not be extrapolated to other futures contracts. ${ }^{21}$

An explanation which is consistent with the empirical results is that there is a default risk premium that affects and is embodied in the futures rates (since the futures contracts themselves are not obligations of the U.S. Government) but that does not affect the forward rates. The default risk would be greater for the later-dated contracts, which involve delivery of Treasury bills not yet issued, than for the contract closest to delivery, which Poole investigated. Although further testing and examination is required to fully explore the implications of the evidence given here, the consideration of the default risk of futures contracts should be a useful starting point.

The results of this study imply that we cannot interpret yields on later-dated 3-month Treasury bill futures contracts as the market's unbiased expectations of future spot rates on 3-month Treasury bills. Futures rates do not necessarily reflect the expected level of future interest rates. However, these results do not conflict with the proposition that changes in market expectations of future interest rates can be inferred from changes in futures rates.

The examination of interest rate expectations embodied in futures rates is therefore more complicated than Poole's results suggest. Furthermore, if default risk is a significant factor affecting futures rates, then estimates of term or liquidity premia in forward rates will not be comparable to the premia embodied in futures rates. This would make the estimation of the levels of expected future interest rates even more difficult. Consequently, policymakers who want to compare their own interest rate forecasts to the market's expectations should use caution in employing futures rates to measure market expectations.

\footnotetext{
"Poole, "Using T-Bill Futures to Gauge Interest-Rate Expectations," p. 15 .
} 